\title{
Dresden Faculty selection procedure for medical students: what impact does it have, what is the outcome?
}

\author{
M. Hansel, S. Klupp, A. Graupner, P. Dieter, T.Koch
}

\begin{abstract}
Summary
Since 2004 German universities have been able to use a selection procedure to admit up to 60 percent of new students. In 2005, the Carl Gustav Carus Faculty of Medicine at Dresden introduced a new admission procedure. In order to take account of cognitive as well as non-cognitive competencies the Faculty used the following selection criteria based on the legal regulations for university-admissions: 1. the grade point average of the school-leaving exam (SSC, Abitur), 2. marks in relevant school subjects; 3. profession and work experience; 4, premedical education; and 5. a structured interview. In order to evaluate the effects of the Faculty admission procedures applied in the years 2005, 2006 and 2007, the results on the First National Medical Examination (FNME) were compared between the candidates selected by the Faculty procedures (CSF-group) and the group of candidates admitted by the Central Office for the Allocation of Places in Higher Education (the ZVS group, comprising the subgroups: ZVS best, ZVS rest and ZVS total). The rates of participation in the FNME within the required minimum time of 2 years of medical studies were higher in the CSF group compared to the ZVS-total group. The FNME pass rates were lowest in the ZVS rest group and highest in the ZVS best group. The ZVS best group and the ZVS total group showed the best FMNE results, whereas the results of the CSF-group were equal or worse compared to the ZVS rest group. No correlation was found between the interview results and the FNME results. According to studies of the prognostic value of various selection instruments, the school leaving grade point average seems the best predictor of success on the FNME. In order to validate the non-cognitive selection instruments of the Faculty procedure, complementary instruments are needed to measure non-cognitive aspects that are not captured by the FNME-results. (Hansel M, Klupp S, Graupner A, Dieter P, Koch T. Dresden Faculty selection procedure for medical students: what impact does it have, what is the outcome? Netherlands Journal of Medical Education 2010;29(1):66-72)
\end{abstract}

\section{Introduction}

The number of applicants for places in medical schools in Germany substantially exceeds the numbers of available places. Admission is therefore subject to restrictions (numerus clausus) and the application process is administered by a federal organization, the Central Office for the Allocation of Places in Higher Education (Zentralstelle für die Vergabe von Studienplätzen (ZVS). ${ }^{1}$ After a new law defining the framework for higher education was amended in $2004,{ }^{2}$ the criteria for the central admission became the following (Figure 1): a) different quotas for students from outside the European Union (EU), other places and pre allocated places, b) the grade point average (GPA) based on the secondary education school-leaving certificate (SSC, Abitur - in Germany a 6point grading scale is used to evaluate school performance: 1 = excellent; 2 = 
good; 3 = fair; 4 = satisfactory; 5 = unsatisfactory; 6 = poor) (group ZVS best), c) waiting time (group ZVS waiting time) and d) an autonomous Faculty admission procedure. Each student can apply for admission to six medical schools, ranking these schools in order of preference.

In 2005, the Carl Gustav Carus Faculty of Medicine at Dresden introduced an autonomous admission procedure. The main goal was to take into account, besides cognitive competencies (mainly reflected in the GPA), non-cognitive abilities with relevance to the medical profession. ${ }^{3}$ Based on the university admission rules according to the law of the state of Saxony (Sächsisches Hochschulzulassungsgesetz, HZG) ${ }^{4}$ an autonomous admission process must include at least one of the following criteria or instruments: GPA of the schoolleaving exam (SSC, Abitur), marks in relevant school subjects, professional and work experience, preparatory training, a profession-specific aptitude test or an interview. After considering the feasibility of the different criteria, the Faculty decided to use all instruments except for the profession-specific aptitude test.

Applicants listing Dresden as their first preference on the list of medical schools submitted to the ZVS entered stage 1 of the Dresden admission procedure. Since by law the GPA must have the highest impact on admission decisions, a predefined number of students were selected for the admission procedure based on their GPA.

The two-part admission process comprises assessment of cognitive and noncognitive (behavioural and attitudinal) competencies.

\section{Methods}

In 2005, all 230 applicants received a questionnaire in part 1 of the admission procedure, asking them to list their marks in specific subjects, mathematics, physics, chemistry and biology in particular. Additional information was gathered about previous professional and/or workexperience as well as premedical training or social work. In part 2, all candidates were invited to for a structured interview by faculty members. All interviews consisted of the following four sections: 'Introduction and biographical background', 'Reasons for studying', 'General interests and general knowledge' and 'Situational questions'. In each section the interviewers asked pre-defined questions. For the final ranking, the scores on part 1 (questionnaire) and part 2 (interview) were summed.

In 2006, the admission process was modified. In contrast to the previous year,

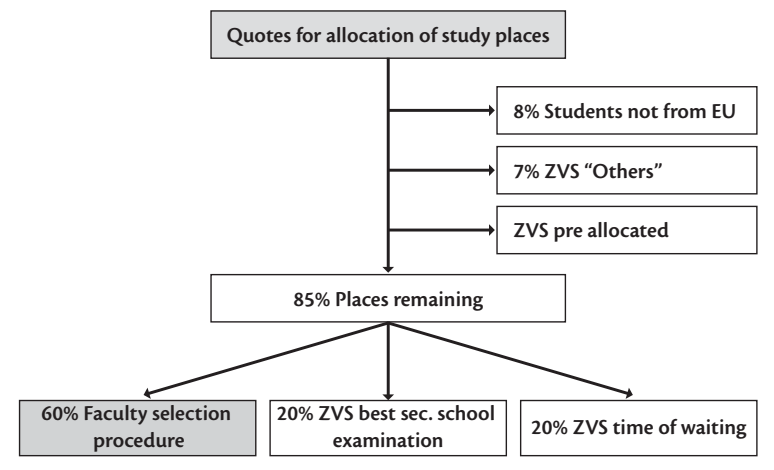

Figure 1. System of allocation of medical school places in Germany since 2005. 


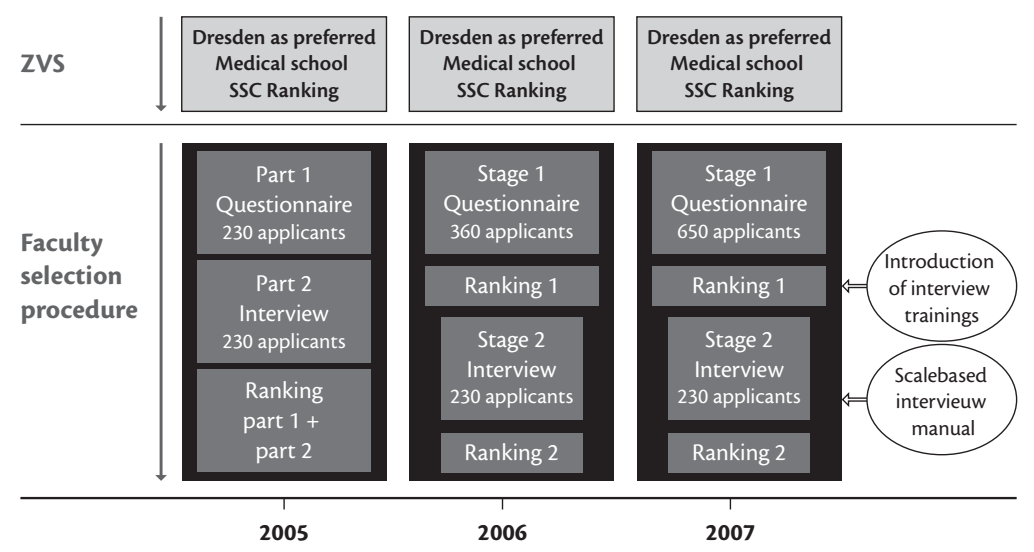

Figure 2. The Dresden Faculty selection procedures of the years 2005, 2006 and 2007. The numbers of applicants are approximate numbers.

the results of the questionnaire in stage 1 were used to rank the candidates for stage 2 (Ranking 1). Of the 360 candidates completing the same questionnaire as the one used in 2005, 230 candidates were invited to participate in the interviews in stage 2 . The interview-scores were used for Ranking 2 and the final admission decision. In order to ensure adherence to a certain standard, both in the interviews and in the diagnostic judgements, all Faculty members who interviewed applicants were trained in interview-techniques by an expert.

In 2007, approximately 650 applicants were invited to complete the questionnaire of stage 1 . Based on the ranking in accordance with the questionnaire results (Ranking 1), 230 candidates were selected for interviews (stage 2). The only modification in stage 2 was increased standardization of the interview structure in order to diminish the subjectivity of interview content and judgement. All Faculty members who interviewed applicants received a scoring manual and took part in a training session in which they interviewed simulated students in order to become acquainted with the new manual. For each criterion of the four interview sections, interviewers had to assess the applicant's performance on an ordinal scale.

In order to evaluate our Faculty selection procedure, the participation rates, pass rates and results in the First National Medical Examination (FNME) of students taking the exam within the required minimum time of two years of study were compared between different groups of students (Tables 1-4). The total number of students admitted by the ZVS is represented in group 1, which is divided into two subgroups: (a) admission based on GPA (ZVS best) and (b) admission based on ZVS waiting time plus ZVS others plus ZVS pre-allocated (ZVS rest). Group 2 contains all medical students admitted through the Faculty admissions procedure (self selected group).

\section{Statistical analysis}

Differences between the groups in GPA were tested with the Mann-Whitney U test and Spearman's rho was used to analyze correlations between GPA and FNME and between the results of the Faculty admission procedure and the FNME results. 


\section{Results}

\section{FNME participation rates}

In order to evaluate the performance of the different groups of students in the first two years of the Dresden medical curriculum we determined students' FNME participation rates within the required two-year period (Table 1).

In the groups of students admitted in 2005-2007 the participation rates are higher for the self selected group (group 2) than they are for the ZVS total (group 1). It is clear that group $1 \mathrm{~b}$ (ZVS rest) has the greatest impact on this difference. A comparison of the self-selected group (group 2) with the ZVS best group (group 1a) shows that in the cohorts admitted in 2005 and 2007 the participation rate is slightly higher in group 1a compared to that in group 2, whereas in the 2006 cohort both groups show almost the same participation rates.

The GPAs of the students taking the FNME within the required two-year period show no difference between the ZVS total and the self-selected group (Table 2).

\section{FNME results}

The FNME results are shown for both the written and the verbal part in table 3 . The ZVS total group (group 1) shows a mar-

Table 1. Percentages of students admitted by the ZVS and the Dresden Faculty, respectively, which took the FNME within the required two years.

\begin{tabular}{|c|c|c|c|c|}
\hline Group & \multirow[t]{2}{*}{ Year of admission } & \multirow{2}{*}{$\begin{array}{c}2005 \\
N=56 / 87\end{array}$} & \multirow{2}{*}{$\frac{2006}{N=50 / 76}$} & \multirow{2}{*}{$\begin{array}{c}2007 \\
N=62 / 84\end{array}$} \\
\hline 1. & & & & \\
\hline & & $64.4 \%$ & $65.8 \%$ & $73.8 \%$ \\
\hline & a. ZVS best & $N=32 / 36$ & $N=28 / 32$ & $N=32 / 34$ \\
\hline & & $88.9 \%$ & $87.5 \%$ & $94.1 \%$ \\
\hline & b. ZVS rest & $N=24 / 51$ & $N=22 / 44$ & $N=30 / 50$ \\
\hline & & $47.1 \%$ & $50 \%$ & $60.0 \%$ \\
\hline \multirow[t]{4}{*}{2.} & Self-selected group & $N=96 / 127$ & $N=109 / 129$ & $N=99 / 132$ \\
\hline & & $75.6 \%$ & $84.5 \%$ & $75.0 \%$ \\
\hline & All students (global) & $N=152 / 214$ & $N=159 / 205$ & $N=161 / 216$ \\
\hline & & $71.0 \%$ & $77.6 \%$ & $74.5 \%$ \\
\hline
\end{tabular}

$\mathrm{N}=$ students taking the exam / all students in the group.

Table 2. GPAs of students taking the FNME within the required two year period (mean and minimum and maximum).

\begin{tabular}{|c|c|c|c|c|c|c|c|}
\hline \multicolumn{2}{|c|}{ Group } & Year of admission & 2005 & \multicolumn{2}{|c|}{2006} & \multicolumn{2}{|c|}{2007} \\
\hline & & SSC & & SSC & & SSC & \\
\hline & & mean & $\min -\max$ & mean & $\min -\max$ & mean & $\min -\max$ \\
\hline \multirow[t]{4}{*}{1.} & ZVS-total & $1.4 \pm 0,6$ & $1.0-3.1$ & $1.6 \pm 0.8$ & $1.0-3.6$ & $1.5 \pm 0.7$ & $1.0-3.3$ \\
\hline & a. ZVS-best & $1.0 \pm 0,5$ & $1.0-1.1$ & $1.0 \pm 0.4$ & $1.0-1.1$ & $1.0 \pm 0.5$ & $1.0-1.1$ \\
\hline & b. ZVS-rest & $1.9 \pm 0,6$ & $1.1-3.2$ & $2.4 \pm 0.6$ & $1.2-3.6$ & $2.0 \pm 0.6$ & $1.2-3.3$ \\
\hline & 2. Self-selected group & $1.4 \pm 0,1$ & $1.1-1.8$ & $1.6 \pm 0.3$ & $1.0-3.1$ & $1.6 \pm 0.3$ & $1.1-2.0$ \\
\hline
\end{tabular}


ginally but significantly better performance in the written part over all three years compared to the self-selected group. No difference is found between the FNME results of group $1 \mathrm{~b}$ (ZVS rest) and the selfselected group.*

Table 4 shows that in the cohorts admitted in 2005 and 2006 the passing rates (percentage of students passing the FNME within the required two years of study) are highest in the ZVS total groups and in the ZVS best groups. However, in the cohort admitted in 2007, the self-selected group does better or equally well compared to the ZVS total group.
Comparison between GPA and FNME (written part) results shows a significant correlation in group 1 and in group 2 (Table 5).

However, when the different Faculty admission instruments of the Dresden selection process and the FNME results (written and verbal part) are compared (Table 6), no correlations are found, apart from a significant low negative correlation of apprenticeship with the verbal part of the FNME in the cohort admitted in 2005 and with the written part of the FNME in the cohort admitted in 2006.

Table 3. Differences between the ZVS total group and the self-selected group in FNME results (means and standard deviations) of the cohorts admitted in 2005, 2006 and 2007.

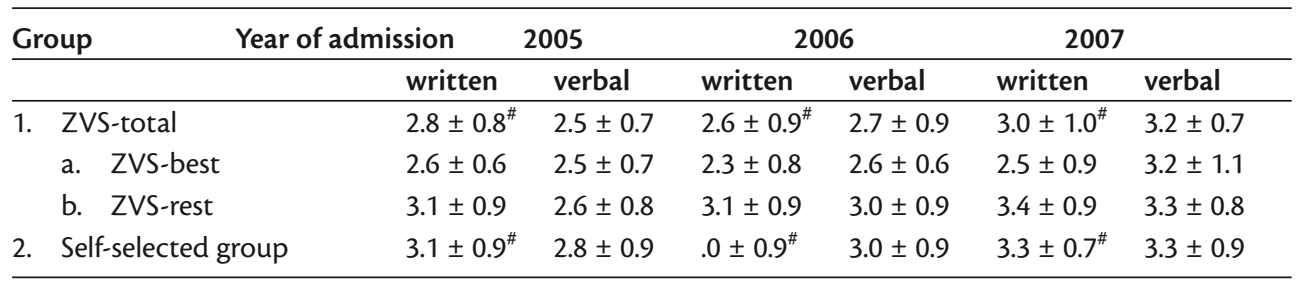

\# = significantdifference $(\mathrm{P}<.05)$

* In Germany a 5-point grading scale is used to evaluate medical school performance: 1 = excellent; 2 = good; 3 = satisfactory; 4 = sufficient; 5 = deficient

Table 4. Percentage of students passing the FNME in the admission cohorts of 2005, 2006 and 2007.

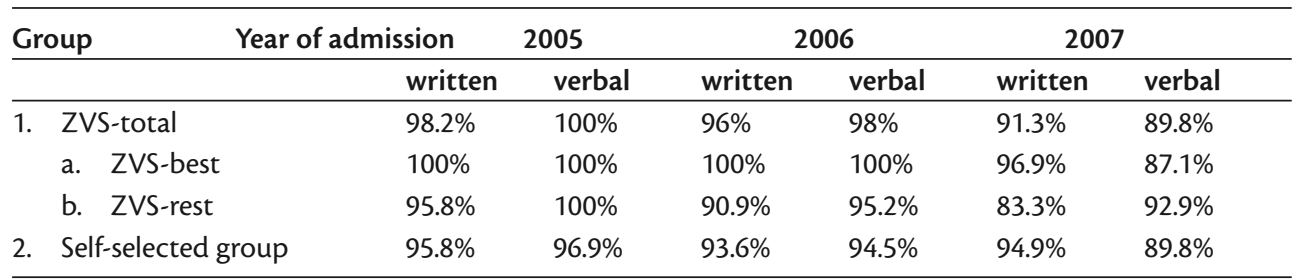

\footnotetext{
* The project group consisted of professor C.L.A. van Herwaarden (chairperson), professor R.F.J.M. Laan (project coordinator), drs. R.R.M. Leunissen (secretary), dr. W.M.C. Mulder, dr. H. de Vries, professor F.G.M. Kroese, professor J.H. Bolk, professor B.G.M. van Engelen, professor A.C. Nieuwenhuijzen, professor T.J.M. Helmerhorst, professor E.A.M Sanders and professor N.S. Klazinga. Advisory members were dr. L. Wigersma (Royal Dutch Medical Association), dr. M.A.G. van den Berg (Clients Council of University Medical Centres), drs. L. Schöffer (National Medical Students Platform), dr. R.A.F. de Lind van Wijngaarden (National Interns Platform) and D.I.M. Hoefnagel LL.M (Ministry of Health, Welfare and Sports).
} 
Table 5. Correlations between GPA and FNME results in the ZVS total group and the self-selected group.

\begin{tabular}{lllll}
\hline First exam (4th semester) & Year of admission & 2005 & 2006 & 2007 \\
\hline & GPA & GPA & GPA \\
\hline Written part & $.27^{* *}$ & $.34^{* *}$ & $.38^{* *}$ \\
Verbal part & .12 & .14 & .12 \\
\hline
\end{tabular}

** indicates a significant correlation $(p<.01)$

Table 6. Correlations between Faculty admission instruments of the Dresden selection procedure and the FNME results.

\begin{tabular}{|c|c|c|c|c|c|c|}
\hline \multirow{2}{*}{$\begin{array}{l}\text { Faculty Admission } \\
\text { Instruments } \\
\end{array}$} & \multicolumn{2}{|c|}{ ar of admission } & 2005 & \multirow{2}{*}{$\begin{array}{c}2006 \\
\text { verbal } \\
\mathrm{N}=109\end{array}$} & \multicolumn{2}{|c|}{2007} \\
\hline & $\begin{array}{l}\text { written } \\
\mathrm{N}=96\end{array}$ & $\begin{array}{l}\text { verbal } \\
N=96\end{array}$ & $\begin{array}{c}\text { written } \\
\mathrm{N}=109\end{array}$ & & $\begin{array}{l}\text { written } \\
\mathrm{N}=99\end{array}$ & $\begin{array}{l}\text { verbal } \\
N=98\end{array}$ \\
\hline GPA & .08 & -.15 & .19 & .07 & .07 & .10 \\
\hline Science marks & .00 & .04 & .14 & .08 & -.01 & .05 \\
\hline Apprenticeship & -.17 & $-.22^{*}$ & $-.21^{*}$ & $-.18^{*}$ & .07 & .11 \\
\hline Premedical training/social work & .18 & .19 & .05 & -.01 & -.00 & -.10 \\
\hline Awards & .12 & .16 & .15 & .14 & -.07 & -.15 \\
\hline Interviews & .00 & .14 & .03 & .05 & .05 & .07 \\
\hline
\end{tabular}

* indicates a significant $(p<.05)$ correlation

\section{Discussion}

The results (Table 2) show that the participation rates in the FNME within the regular period of study are higher in the selfselected group (group 2) compared to the ZVS total group (group 1), suggesting that the students selected by the Dresden Faculty selection procedure are better suited to meet the requirements of the Dresden curriculum in the first 2 years. The participation rate of the self-selected group is similar to that of the ZVS best group (group 1a), while the lowest participation rate is found in the ZVS rest group.

However, in the 2005 and 2006 cohorts, the passing rates of the self-selected group (Table 4) are slightly lower compared to those of the ZVS total group. In the 2007 cohort, the passing rate of the self-selected group is slightly higher for the writ- ten part and equal for the verbal part compared to the passing rate of the ZVS total group. Overall, the passing rate is highest for the ZVS best group (group 1a) and lowest (in the written part) for the ZVS rest group (group 1b).

Comparison of the FNME results (Table 3) shows that the ZVS best group and the ZVS total group obtain the best results, whereas the self-selected group has results that are equal to or worse than those of the ZVS rest group. This may be due to the fact that GPA and FNME results both reflect mainly cognitive abilities. ${ }^{5}$ These results are also consistent with earlier findings demonstrating that GPA is the best predictor of a pass on the FNME. ${ }^{6-7}$ These findings may be limited to the FMNE, which could be demonstrated by studies showing a high correlation of GPA 
with FNME results early in the medical curriculum but not in later curricular years. $^{8}$

Likewise no positive correlation is found between the results of the interviews and the FNME results. This may be due to heterogeneity in judgements, as has been described in the literature. ${ }^{9}$ Standardization of interviews and training of the Faculty members had no positive impact. In order to increase the objectivity of the Dresden selection process we introduced multiple mini-interviews in 2009. ${ }^{10}$

One goal of the Dresden admission process is to take account of applicants' non-cognitive competencies, which are considered essential for medical students and future doctors, in addition to their cognitive competencies as reflected in the GPA. However, a certain level of cognitive performance is needed to pass the FNME, especially the written multiple choice question part of the exam, which does not correlate with non-cognitive competence. ${ }^{11}$ In order to validate our Faculty selection instruments, we need additional criteria covering specifically the non cognitive competencies.

We will therefore continue to analyze the different cohorts during the clinical years of the curriculum in order to validate our selection instruments by looking at students' competencies during the clinical clerkships/electives. ${ }^{12}$ Additionally, the Second National Medical Exam (SNME), which is taken after 6 years of education and which consists of a written and an oral part, will be used to analyze differences between the cohorts.

\section{References}

1. http://www.zvs.de

2. Hochschulrahmengesetz HRG, http://www.bmbf. de/de/1600.php.

3. The CanMEDS Physician Competency Framework. http://rcpsc.medical.org/canmeds/index.php.
41. Sächsisches Hochschulzulassungsgesetz. https:// tu-freiberg.de/zuv/service/pdf/gesetze/saechs-hg.pdf.

51. Rindermann H, Oubaid V. Auswahl von Studienanfängern durch Universitäten - Kriterien, Verfahren und Prognostizierbarkeit des Studienerfolgs. Zeitschrift für Differentielle und Diagnostische Psychologie 1999; 20:172-191. [Admission procedures used by universities - selection criteria and procedures and their prognostic value for study success. Journal of Differential and Diagnostic Psychology].

61. Strauß B, Braehler E. Der Kampf um die Besten. Das neue Zulassungsverfahren zum Medizinstudium.[Fighting for the best: the new procedure for the selection of medical students]. Psychother Psychosom Med Psychol 2005; 55 (7): 321-323.

71. Trost G, Klieme E, Nauels H-U. The relationship between different criteria for admission to medical school and student success. Assessment in Education 1998;5:247-254.

81. Brandstätter H \& Farthofer A. Erste Prufungen weiterer Studienerfolg. Psychologie in Erziehung und Unterricht, 2003;50:58-70.

91. Huffcutt AI, Arthur W. Hunter and Hunter (1984) revisited: Interview Validity for Entry-Level Jobs. J Appl Psychol 1994;29 (2):184-190.

10. Eva K.-W., Rosenfeld,J, Reiter HI, Norman,G. An admissions OSCE: the multiple mini-interview. Med Educ 2004; 38:314-326.

11. Albanese Mark A, Snow Mikel H, Skochelak Susan E, Huggett Kathryn N, Farrell Philip M: Assessing personal qualities in medical school admissions. Acad Med 2003;78:313-21

12. Donnon T, Oddone-Paolucci E, Violato C: A predictive validity study of medical judgment vignettes to assess students' noncognitive attributes: a 3 year prospective longitudinal study. Med Teach 2009; 31(4):e148-155.

The authors:

M. Hänsel, PhD, is dipl.-psych. TU Dresden, studiendekanat, Germany.

S. Klupp, is student, Dresden, Germany.

A. Graupner, PhD, TU Dresden, Germany.

P. Dieter, MD PhD, is professor TU Dresden, Germany.

T. Koch, MD PhD, is professor University Medical Centre, anesthesiology, Dresden, Germany.

Correspondence

Prof. dr. Thea Koch,University Medical Centre Dresden, Fetscherstrasse 74, 01307 Dresde, Germany.

Tel.: ++49-351-458-2785.

E-mail: jessica.hofmann@uniklinikum-dresden-de

No potential conflict of interest relevant to this article was reported 